\title{
O IMPACTO DOS CONCEITOS DE GÊNERO PARA A GARANTIA DOS DIREITOS HUMANOS DE PROTEÇÃO À MULHER
}

\author{
$*$ \\ Analice Schaefer de Moura \\ Universidade de Santa Cruz do Sul-UNISC-Brasil \\ Letícia Thomasi Jahnke \\ Universidade de Santa Cruz do Sul - UNISC - Brasil
}

\section{Resumo}

Se a internacionalização de direitos humanos reconhecidos a toda pessoa é recente, o reconhecimento de direitos particularizados às mulheres é ainda mais. Essa necessidade de direitos que lhe são próprios é necessária para a garantia da igualdade e proteção da mulher, enquanto ser humano que está exposto a agressões muito específicas como violência doméstica, estupro, assédio nos locais públicos, dificuldade de ingresso nos espaços de poder, enfim. A partir dessa premissa, aborda-se no presente artigo os Direitos humanos de mulheres e o sistema jurídico internacional de proteção. Assim, pretende-se responder ao problema: Como a questão de gênero pode impactar os direitos humanos e assegurar a proteção à mulher? Para tanto, pretende-se compreender a atuação do sistema internacional de proteção dos direitos humanos na garantia dos direitos de proteção particulares das mulheres. Deste modo, objetivou-se inicialmente conceituar o que são direitos humanos para, após, compreender a contribuição das tramas de gênero para os direitos humanos das mulheres e seu reconhecimento internacional. A técnica de pesquisa utilizada foi a bibliográfica (artigos e livros) e documental. Por sua vez, o método utilizado foi o hipotético-dedutivo, partindo-se da análise do que são direitos humanos genericamente, para, após, buscar o referencial mais específico no que tange a necessidade do reconhecimento de direitos humanos particularizados às mulheres. Constata-se assim que, embora os movimentos feministas iniciados nos anos de 1960 tenham tido suas conquistas, a proteção e garantia de tais direitos ainda necessita ser efetivada e discutida a fim de evitar o retrocesso social.

Palavras-chave: Direitos humanos das mulheres; empoderamento feminino; igualdade; internacionalização dos direitos humanos.

\section{INTRODUÇÃO}

Homens e mulheres tiveram papéis distintos na formação da sociedade, isso se deu a fatores culturais e biológicos, que influenciaram na conquista (ou não) de direitos. Ao homem, coube o espaço público, externo, de produção, já a mulher foi submetida ao espaço privado, interno, de reprodução. Assim o acesso feminino aos espaços de tomadas de decisão ocorreu tardiamente, o que fez com que seus direitos fossem igualmente reconhecidos mais tarde na história da humanidade. Dessa forma, mulheres no mundo inteiro ainda têm sua 
integridade atingida e estão mais expostas a uma série de agressões na sociedade e no âmbito doméstico, muitas dessas são particulares ao sexo feminino, ou vitimizam mais mulheres do que homens, razão pela qual a necessária proteção de direitos humanos particularizados a este público.

A partir dessa perspectiva, o presente artigo tem como tema os direitos humanos de mulheres e o sistema jurídico internacional de proteção. Deste modo, o pretende-se responder ao problema como a questão de gênero pode impactar os direitos humanos e assegurar a proteção a mulher?

Nesse ínterim, defende-se que os direitos humanos que visam, especificamente a proteção e garantias individuais das mulheres foram traçados em escala mundial por meio de conferências internacionais, daí a importância de estudar a internacionalização de tais direitos, a fim de criar um novo paradigma centrado em todo o contexto social.

No decorrer da pesquisa, foi utilizado como método de abordagem o hipotéticodedutivo. Para tanto, analisou-se o que são direitos humanos genericamente, para, após, buscar o referencial mais específico no que tange a necessidade do reconhecimento de direitos humanos particularizados às mulheres. Utilizou-se como técnica a pesquisa bibliográfica e documental como base teórica do estudo. Foi realizado levantamento bibliográfico, bem como, levantamento documental.

As fontes utilizadas permitiram uma melhor fundamentação no trabalho desenvolvido, bem como, na diversificação da abordagem, para concretizar os objetivos estabelecidos. Além do mais, buscou-se investigar os temas propostos a partir da correlação entre o levantamento do instrumental teórico e os tratados internacionais ratificados sobre direitos humanos de mulheres.

Assim, inicialmente aborda-se o conceito, se é que existe um aceitável por toda doutrina, acerca do que são direitos humanos, a fim de compreendê-los enquanto valores historicamente construídos, analisado assim uma perspectiva histórica da sua construção, para após compreender como são fundamentados.

Após, discute-se a atribuição histórica da mulher na sociedade e sua luta na busca pela concretização e reconhecimento de direitos, abordando-se o papel da mulher na sociedade e a necessidade de direitos humanos particularizados a elas. Por fim, é feito uma análise acerca internacionalização de tais direitos, estudando os principais documentos internacionais que reconheceram direitos específicos às mulheres. 


\section{DIREITOS HUMANOS: DEFINIÇÕES E FUNDAMENTAÇÃO}

Ao se falar em direitos humanos, é possível afirmar que todos possuem uma definição própria do que sejam tais direitos. A essência que viabilizará a concretização, de forma ampla, da cidadania e também da democracia será a incidência dos direitos humanos de maneira intrínseca nas relações humanas.

Sequer na doutrina há consenso na sua definição, tendo em vista que são valores compreendidos além das leis e costumes ou, ainda "postulados primários de toda ordem moral e jurídica-positiva, de cujos limites nenhum poder político pode afastar-se" (GORCZEVSKI, 2009, p. 21).

Portanto, discutir o tema na contemporaneidade nos remete a valorização do ser humano e aos princípios de liberdade e igualdade das revoluções do século XVIII. Embora os últimos séculos tenham sido marcados pela conquista de direitos e valorização da vida, já na Grécia Clássica se encontram escritos sobre a valorização de elementos indissociáveis a condição humana, especialmente a razão e a liberdade política (DUARTE, 2015)

Assim, a sociedade grega antiga contribuiu para noção de direitos humanos, com uma concepção naturalística, que entendia que certos direitos proviam da natureza humana, contudo esses direitos eram apenas reconhecidos aos cidadãos - homens gregos, livres e com posses.

Por sua vez, o Império Romano embora mantivesse o modelo escravagista, permitindo ainda a tortura e uma relativa impunidade a alguns membros de setores privilegiados, contribuiu para o desenvolvimento e positivação dos conceitos gregos, reconhecendo valores que todo o ser humano possui desde o nascimento (GORCZEVSKI, 2009).

Com a queda do Império Romano surge os feudos, em que o senhor feudal era o proprietário da terra e de seus vassalos, essa estrutura pulverizada e fechada de poder impediu grandes construções na seara dos direitos humanos.

Com o crescimento das cidades, e a criação de universidades os feudos acabam perdendo força, iniciando uma nova fase na história da humanidade. Contudo, o marco na proteção dos direitos fundamentais, ocorreu em 1215 com a assinatura da Carta Magna, "fruto da insatisfação dos nobres ingleses contra os abusos de poder do monarca e da 'querela' desse com o clero" (SCHWINN, 2011, p. 659). Seguindo esse movimento, em 1689 é assinado o Bill of Rights, que além de consagrar algumas garantias individuais, pôs fím ao modelo de monarquia absoluta (GORCZEVSKI, 2009). 
Contudo, a transformação dos direitos humanos no que conhecemos atualmente, se deu após as Revoluções Americana e Francesa no século XVIII, mas que ainda não se preocuparam com a condição da mulher, a fim de estabelecer referenciais de igualdade e proteção (DUARTE, 2015).

Importante aqui reconhecer a diferença entre as declarações de direitos humanos da Revolução Americana e da Francesa. Nesse sentido, destaca Arendt (2011) que as declarações francesas enfocaram não somente o seu cidadão, mas todos os homens, portanto com uma ambição mais universalista de reconhecimento dos direitos humanos, por sua vez, os Estados Unidos, enfatizou o Governo, condicionando suas atividades à esses direitos. Ou seja, a Declaração dos Direitos do Homem e do Cidadão francesa estabeleceu direitos que independiam da estrutura política, visando reconhecer direitos inerentes à natureza humana.

A concepção contemporânea de direitos humanos foi inserida na Declaração Universal dos Direitos do Homem de 1948 (posteriormente denominada de Declaração Universal dos Direitos Humanos, proposta por Eleanor Roosevelt, para integrar as mulheres) e espelhada na Declaração de Direitos Humanos de Viena de 1993, e é marcada pela universalidade e indivisibilidade desses direitos. Essa visão é resultado da internacionalização dos Direitos humanos como réplica às barbaridades cometidas durante o nazismo, ou seja, um efeito à Pós-Guerra. (PIOVESAN, 2014)

A Declaração Universal dos Direitos do Homem é referenciada por Norberto Bobbio (1992, p. 28) como sendo "a maior prova histórica até hoje dada do consensus ominiun gentium sobre um determinado sistema de valores". Ainda nesse sentido, o mesmo autor segue o pensamento acerca da Declaração, pois o pensamento:

[...] foi acolhido como inspiração e orientação no processo de crescimento de toda a comunidade internacional no sentido de uma comunidade não só de Estados, mas de indivíduos livres e iguais. Não se tem consciência de até que ponto a Declaração Universal representa um fato novo na história, na medida em que, pela primeira vez, um sistema de princípios fundamentais da conduta humana foi livre e expressamente aceito, através de seus respectivos governos, pela maioria dos homens que vivem na Terra. Com essa declaração, um sistema de valores é - pela primeira vez na história universal, não em princípio, mas de fato, na medida em que o consenso sobre sua validade e sua capacidade para reger os destinos da comunidade futura de todos os homens foi explicitamente declarado. (BOBBIO, 1992, p. 28)

Numa outra visão, acredita-se que por mais força que a Declaração tenha, ela não é considerada um tratado. Nesse sentido, de acordo com Filho (2012, p.109) não possuía força cogente: 
diferentemente dos demais documentos da ONU sobre Direitos Humanos, a Declaração não é um tratado, do ponto de vista formal. Trata-se de uma Resolução não impositiva da Assembleia Geral das Nações Unidas e, portanto, jamais passou pelo processo de ratificação típico dos tratados internacionais (grifo do autor).

Assim, a ONU pretendeu criar um novo tratado de direitos humanos após a Declaração Universal de 1948. Em 1966 foram então finalizados os trabalhos e propostos dois tratados diferentes, a Convenção Internacional de Direitos Civis e Políticos e a de Direitos Econômicos, Sociais e Culturais. Em teoria, a primeira representava os direitos humanos que seriam consagrados pelos regimes capitalistas; a segunda, os consagrados pelos regimes socialistas.

Essa divisão se deu em razão da polarização entre os dois regimes, pretendendo que os estados ao menos assinassem e ratificassem um dos tratados, senão os dois (FERNANDES, 2009). Na América, a primeira tentativa de criar uma organização internacional foi proposta por Simon Bolívar, em 1826 no Congresso do Panamá, que pretendia a criação de uma "estrutura institucional que integrasse as colônias espanholas, evidentemente excluindo o Brasil e Estados Unidas da América" (GORCZEVSKI, 2009, p. 167). Por pressão dos dois Estados excluídos, a intenção restou frustrada.

Anos após, a ideia foi concretizada na IX Conferência Internacional Americana realizada em Bogotá, em 1948, quando os Estados americanos se reuniram com o objetivo maior de construir a Organização dos Estados Americanos - OEA, agora com todos os países integrantes do continente. A Declaração Americana dos Direitos e Deveres do Homem de 1948 foi o ponto de partida do sistema interamericano, sendo que a Carta da OEA e o Pacto Americano de Soluções Pacificas (Pacto de Bogotá) são frutos dessa Conferência (CORREIA, 2008).

Diante da sucinta contextualização histórica, constata-se que os Direitos Humanos nascem na medida das necessidades humanas e integram um processo que comporta reconstruções que envolvem uma filosofia dos valores morais, simbolizados pela luta e ação social (PIOVESAN, 2014). Nesse sentido, afirma Arendt (1979, p. 134) que os direitos humanos "são um dado, são uma invenção humana em constante processo de construção e reconstrução". Deste modo:

no amanhecer histórico dos direitos do homem e em seu desenvolvimento posterior, os direitos humanos foram, em primeiro lugar, demandas coletivas, reivindicações arrancadas do poder contra a vontade desse, conquistas da razão frente à barbárie. (JULIOS-CAMPUZANO, 2008, p. 117) 
Nesse sentido, esclarece Piovesan (2014) que os direitos humanos clamam por um reconhecimento universal, a fim de garantir sua aplicação na proteção de qualquer pessoa, já a indivisibilidade é característica dos direitos humanos porque a garantia dos direitos civis e políticos é condição para a observância dos direitos sociais, econômicos e culturais.

Contudo, o reconhecimento dos direitos humanos como uma questão internacional encontrou resistência, sobretudo, em face da noção de soberania estatal. Porém, essa oposição foi perdendo espaço para a compreensão de que os direitos humanos transcendem as fronteiras de qualquer Estado. Tanto que, "modernamente, a comunidade internacional não tem aceitado que o problema da violação dos direitos humanos seja uma questão de competência exclusiva dos Estados" (GORCZEVSKI, 2009, p. 151), em verdade, é um problema de toda a comunidade internacional.

Independente das diversas conceituações do que são direitos humanos, pode-se afirmar sua existência, e a relevância de sua proteção, gozam de unanimidade. E, muito embora, o conceito contemporâneo de direitos humanos tenha surgido no século passado, a noção de proteção ao ser humanos é tão antiga que se perde no tempo (SCHWINN, 2011). Contudo,

\footnotetext{
na contemporaneidade, a esfera pública - espaço - é palco de intensas mudanças: novos papeis, relações e modelos familiares, comunicação e tecnologias, políticas públicas articulam-se com o terceiro setor, a globalização contribui para a formação de culturas híbridas, a vulnerabilidade econômica e dos territórios; em resumo, o Estado e seus agentes encontram-se em transição, enfrentando incertezas e instabilidade. (DUARTE, 2015, p. 145)
}

Esse novo paradigma, reflete-se na necessária a busca por uma fundamentação dos direitos humanos que tem sido, em todos os momentos e por todos autores, alvo do pensamento filosófico. Basicamente as teorias de fundamentam tais direitos, são dividas grosseiramente em duas correntes, denominadas de jusnaturalismo e juspositivo e, em uma terceira mais nova, chamada de teoria das necessidades.

O Jusnaturalismo foi a primeira fundamentação para os direitos do homem e a que mais influenciou. Entende que os direitos são anteriores ao Estado; o homem já os possuía na natureza. As teses jusnaturalistas iniciam-se na própria denominação de direito natural criada pelos gregos, e perpassa a ordem de existência de um ser superior até o jusnaturalismo racional (GORCZEVSKI, 2009).

A teoria jusnaturalista se subdivide em diversas ramificações, embora defenda suscintamente que os direitos naturais são inerentes à natureza humana, e por esta razão o 
direito é anterior ao Estado (FERNÁNDEZ-LARGO, 2006). Pérez-Luño, (1999) acrescenta que a positivação dos direitos humanos fundamentais se apresenta, a partir dessa visão, como reconhecimento por parte do Estado, de umas exigências jurídicas prévias que se consagram como normas positivas para melhor garantia de sua proteção. No mesmo sentido, define Herkenhoff (1994, p. 30).

Direitos humanos [...] são aqueles direitos fundamentais que o ser humano possui [...] por sua própria natureza humana, pela dignidade que a ela é inerente. São direitos que não resultam de uma concessão da sociedade política. Pelo contrário, são direitos que a sociedade política tem o dever de consagrar e garantir.

Contrário ao elemento da natureza humana e dos poderes divinos, o positivismo acredita na realidade fática como única fonte de verdade, e portanto consideração pela Ciência Jurídica, reduzindo o direito à norma, como a desconsideração das questões éticas, políticas e sociológicas na esfera do direito. (GORCZEVSKI, 2009). O positivismo pretende a separação entre direito e moral, embora existam diversas correntes dentro do positivismo, ele possui importante meio de concretização dos direitos humanos:

É incontestável que os direitos humanos somente ganham concretude, portanto exigibilidade, quando expressos em lei e integram determinada ordem jurídica, isto é, quando passam da sua dimensão axiológica a uma dimensão normativa. Assim, deve-se atribuir ao positivismo a tarefa única de trazer ao mundo jurídico aqueles valores identificados como direitos humanos. (GORCZEVSKI, 2009, p. 99).

Diante do aqui apresentado, é possível compreender que os direitos humanos são construídos historicamente. Assim, eles são impactados por processos históricos que delimitam seu conceito e ressignificação. Foram as mudanças sociais, portanto, que permitiram a incorporação das demandas feministas por reconhecimento de direitos humanos particularizados às mulheres. Assim, nota-se a necessária inclusão de uma perspectiva de gênero na definição do conteúdo dos direitos humanos, é o que segue.

\section{O IMPACTO DOS CONCEITOS DE GÊNERO PARA CONCRETIZAÇÃO DOS DIREITOS HUMANOS DAS MULHERES}

Conforme acima exposto, o reconhecimento dos direitos humanos à todas as pessoas é um marco recente na história da humanidade, contudo, pode-se afirmar que a busca da implementação dos direitos humanos das mulheres é ainda mais nova, o que lhe dá certa 
insegurança. Nesse sentido, a história das mulheres foi escrita a partir da perspectiva dos homens, o que dificultou ainda mais a garantia de seus direitos.

Historicamente, homens e mulheres ocuparam espaços diferenciados na sociedade, o que acarretou em vivências distintas, que se transformaram em direitos garantidos. Em decorrência disso, o homem teve uma maior inserção nos espaços públicos de tomada de decisões, dessa forma os debates políticos e filosóficos sobre os direitos humanos deram-se a partir de uma perspectiva masculina. Portanto, é necessário compreender como a sociedade organizou-se de modo a visibilizar a figura e a participação feminina e, consequentemente, seus anseios na concretização de seus direitos.

Cabe salientar que nessa caminhada em busca de reconhecimento, o caminho foi árduo, tendo em vista que a sociedade patriarcal não aprovava a inserção nem a participação da mulher em questões políticas sociais. Pois desde as antigas civilizações, em sua maioria, o papel da mulher se restringia ao lar e ao cuidado dos filhos.

De acordo com Simone de Beauvoir, a mulher sempre exerceu um papel limitado a passividade, sendo que a vida, a força e a energia, por exemplo, eram atreladas a figura masculina. Nesse sentindo, a sociedade espera da mulher um determinado tipo de comportamento que não extrapole os limites dados a ela. Ou seja:

\footnotetext{
O encargo que a sociedade impõe à mulher é considerado como um serviço prestado ao esposo: em consequência, ele deve à esposa presentes ou uma herança e compromete-se a sustenta-la; é por seu intermédio que a sociedade se desobriga em relação à mulher que lhe entrega. Os direitos que a esposa adquire cumprindo seus deveres traduzem-se por obrigações a que o homem se submete. (BEAUVOIR, 1949, p.549)
}

O pensamento moral propagado pela Igreja Católica foi marcante no desenvolvimento social do Brasil, e por esta razão vige em nosso país a cultura patriarcal (PENIDO, 2006). Esse pensamento foi amplamente difundido pelos princípios racionais do liberalismo durante e pós Revolução Francesa, que sempre atribuíram uma relevância notável na praxe cultural e ideológica cotidiana.

A esse respeito, esclarece a autora que o patriarcado é uma forma de organização e dominação social, cuja autoridade está centrada no patriarca de uma comunidade familiardoméstica (PENIDO, 2006). Esse sistema institucionaliza e legitima o domínio masculino sobre as outras parcelas sociais: as mulheres (pelo marido) e as crianças (pelo pai) (THERBORN, 2006).

Nesse mesmo sentido, Pateman (1993) afirma que, além de cultural, a diferença sexual é também uma diferença política, a qual se acha relacionada com a falta de liberdade e 
de direitos das mulheres e a sua sujeição perante o sexo masculino. A subordinação das mulheres perante os homens surgiu de uma relação de poder entre os sexos.

Ou seja, embora a desigualdade de gênero esteja presente no mundo de maneira geral, a forma como ocorre é diferente entre os países. A assimetria entre o acesso a oportunidades econômicas de homens e mulheres é influenciada por aspectos institucionais especialmente pelo direito, pela economia e por questões sociais, que se estendem ao acesso ao poder pela participação política.

O mundo, porém, não é ou era igualmente patriarcal. O poder dos pais, irmãos, maridos e filhos adultos, embora tenha predominando em toda parte, de fato possuía aspectos e características diferentes entre as classes e culturas (THERBORN, 2006). Contudo, a autora admite que as principais civilizações ocidentais negligenciaram a mulher, principalmente quanto a seus direitos (THERBORN, 2006). Exemplo disso é que, "por longos anos, elas eram tidas como propriedades de seus maridos os quais detinham amplos e irrestritos poderes sobre elas" (AQUINO; PORTO 2013).

Por muitos anos (se não o é até hoje), as mulheres eram estereotipadas como fracas, submissas, passivas e sem poder político. Ao invés de receberem educação formal, "eram treinadas para o casamento para administrar a casa, criar os filhos, e tolerar as relações extramatrimoniais do marido com as escravas" (DESOUZA; ROSA, 2000, p. 486). Foi somente a partir da era Imperial, as mulheres lutaram para ampliar seus papéis na sociedade no Brasil.

Já na Europa, por volta de 1900, a família europeia tinha sido submetida a pelo menos três grandes mudanças institucionais e econômicas, a proletarização, a urbanização e a industrialização (THERBORN, 2006, p. 41).. Ambas desafiaram o patriarcado de formas diferentes, iniciando o enfraquecimento desse modelo de organização social.

A autora ainda afirma que as mudanças mais drásticas quanto a história de gênero e às relações geracionais, na esfera global, se deram notadamente no final do século XX, com o declínio do patriarcalismo (THERBORN, 2006). Ressalta-se, que embora ainda exista a diferença de gênero na sociedade moderna, os últimos séculos foram marcados por grandes avanços e conquistas originadas da luta de mulheres que resolveram enfrentar a realidade da sua época, abandonando os estereótipos baseados na cultura patriarcal e para ocupar o seu espaço na esfera pública (AQUINO; PORTO, 2013).

Constata-se, que os valores sociais ainda cultivam a violência. Isso porque a desigualdade de gênero ocorre no exercício de poder, levando a essa relação de dominação que não é somente restrita ao ambiente doméstico, mas presente nos espaços públicos, no mercado de trabalho, no campo político, nas escolas, universidade, e inclusive nas políticas 
públicas. No caso brasileiro, por exemplo, ainda existem cicatrizes históricas da desigualdade inclusive no plano jurídico. Desse modo, o processo de violência entre os sexos, está atrelado a estereótipos culturais que estabelecem hierarquia entre o masculino e o feminino.

Conforme acima descrito, a noção de Direitos Humanos desenvolveu-se a partir do final do Século XVIII, com a Declaração Americana de Virgínia, de 1776, e a Declaração Francesa, de 1789, responsáveis por transforar o sentido dado a condição humana da pessoa. Foi especialmente a Declaração Universal dos Direitos do Homem, em 1789, que visava garantir a igualdade entre as pessoas, independentemente do seu status social ou econômico. Embora a igualdade de gênero, não tenha sido uma preocupação do movimento francês, a Declaração, ao trazer a questão da igualdade, dentro da perspectiva universal que a declaração francesa pretendia alcançar, foi um passo importante para que se começasse a pensar o papel da mulher na sociedade.

No entanto, tais ideias ficaram adormecidas, sendo retomadas somente após a II Guerra Mundial, com o surgimento, em 1948, da Declaração Universal dos Direitos Humanos, aprovada pela Assembleia Geral das Nações (AQUINO; PORTO 2013). Contudo, o enfoque sobre os direitos das mulheres permaneceu no âmbito público, estabelecendo-se a proteção dos indivíduos perante seus Estados, ficando as questões relativas à esfera privada, que afetam especialmente as mulheres, invisibilizadas (GONÇALVES, 2011).

De todo modo, a declaração inaugurou uma nova fase nos direitos humanos das mulheres, estabelecendo no seu artigo 2 o princípio da igualdade independentemente de sexo. Além do mais, a declaração inovou ao dispor no artigo 16 sobre direitos relacionados a constituição da família:

(1) (...) Homens e mulheres de idade plena têm o direito de se casar e de fundar uma família sem nenhuma limitação de raça, nacionalidade ou religião. Eles são portadores de direitos iguais ao se casar, durante o casamento e em sua dissolução.

(2) O casamento só poderá ser realizado com o livre e pleno consentimento dos pretendentes. (THERBORN, 2006, p. 116)

A pauta do que constituem direitos humanos seria diferente se as mulheres tivessem interagido ativamente nesse processo desde o início. Isso porque, mesmo que as mulheres possam ser vítimas de violações de direitos humanos que atingem os homens, elas experimentam ainda, pela sua capacidade biológica (especialmente reprodutiva) e pela construção social e cultural, formas distintas de violações aos direitos humanos (GONÇALVES, 2011). As mulheres são muitas vezes privadas da sua autonomia sobre seu próprio corpo, sexualidade e da tomada de decisões que lhes dizem respeito; sofrem abusos e 
assédio em casa, no trabalho, na rua; ofensas que muitas vezes não são reconhecidas como ofensas aos direitos humanos.

Importante, nesse sentido a analise de Duarte (2015, p. 142):

Temas como aborto, estupro, violência doméstica, assédio sexual e moral expressam a gravidade de agressões a direitos das mulheres, que não mais se calam, mas que, enquanto humanas, guardam um mínimo de pudor e direito de silêncio sobre as próprias experiências, situadas na esfera da intimidade e dignidade humanas.

A inclusão da temática de gênero nos direitos humanos se deu a partir das reinvindicações dos movimentos feministas a partir da década de 1960, chegando "inclusive a cunhar a insígnia 'sem as mulheres, os direitos não são humanos"” (GONÇALVES, 2011, p. 64). Já no Brasil, esse novo movimento feminista emergiu a partir dos anos 1970. O Zeitgeist (espírito dos tempos) propiciou um grande avanço: as mulheres de classe média, de nível universitário, e mulheres pobres, sem educação, organizaram movimentos para que suas reivindicações políticas feministas fossem incluídas em pauta no sistema político brasileiro (DESOUZA, ROSA, 2000).

O movimento feminista, através da militância, bem como pela academia, permitiu uma discussão sobre os papéis femininos e masculinos na sociedade, e como isso influenciava na garantia de direitos e responsabilidades. Em todas as partes dos continentes, novas iniciativas legislativas começaram a surgir em defesa dos direitos das mulheres (THERBORN, 2006). O Ano Internacional da Mulher seguiu-se a Década da Mulher, de 1975 a 1985, em que o envolvimento das Nações Unidas promoveu a preocupação dos governos com a desigualdade de gênero (THERBORN, 2006).

Deste modo, verifica-se que a reinvindicação de direitos particularizados às mulheres se desenvolveu a partir de suas necessidades concretas, num ambiente político que até pouco tempo não era ocupado por este público. Nesse sentido, a importância das mudanças legislativas quando feitas dentro de uma estrutura global de suporte que "promova mudanças simultâneas nas esferas cultural e social e, via de consequência, na esfera político-econômica" (PENIDO, 2006, p. 270).

A Assembleia Geral das Nações Unidas, em 7 de novembro de 1967, aprovou a "Declaração sobre a eliminação da discriminação contra a mulher". No seu primeiro artigo, o documento declara que "a discriminação contra a mulher nega ou limita sua igualdade de direitos com o homem, é fundamentalmente injusta e constituiu uma ofensa à dignidade humana" (HERKENHOFF, 2013, p. 109). Porém, em se tratando de mera declaração o 
documento não teve relevante significado na concretização dos direitos humanos das mulheres.

O marco legislativo internacional de proteção aos direitos humanos de mulheres foi, então, a aprovação no âmbito das Nações Unidas da Convenção sobre a Eliminação de Todas as Formas de Discriminação contra a Mulher, aprovada em 1979, que conta com 170 EstadosPartes, o que inclui o Brasil, que a ratificou em 1984. Essa Convenção foi resultado de diversas reinvindicações do movimento de mulheres, a partir da primeira Conferência Mundial sobre a Mulher realizada no México, em 1975 (THERBORN, 2006).

Frise-se, contudo, que no plano dos direitos humanos, esta foi a Convenção que mais recebeu reservas por parte dos Estados signatários, especialmente quanto à igualdade entre homens e mulheres na família (PIOVESAN, 2006). Percebe-se com isso, como a efetivação dos direitos humanos das mulheres está condicionada à dicotomia entre os espaços públicos e privado, que, em muitas sociedades, confina a mulher ao espaço exclusivamente doméstico da casa e da família.

Nesse cenário, a Conferência realizada, em 1975, no México, trouxe como principal resultado o lançamento do "Plano da Ação Mundial" feminista. Como corolário desse Plano, propôs-se a "Década da Mulher". A Conferência do México deu início a um novo período, seguindo-se duas outras Conferências de destaque, a de Copenhague, em 1980, e a de Nairóbi, em 1985.

Nesse sentido, em uma conjuntura fortemente marcada pelo debate acerca da questão dos Direitos Humanos, não se pode deixar de mencionar a correlação existente entre os temas apontados, haja vista que, somente em 1993, na Conferência Mundial de Direitos Humanos, realizada em Viena, os direitos das mulheres foram reconhecidos como Direitos Humanos (GONÇALVES, 2011). Isso tudo é consequência lógica de uma reflexão atual que leva o ser humano a repensar sobre si mesmo, bem como sobre suas atitudes, colocando-se como alguém capaz e responsável por aquilo que pensa, fala e faz. E, sob esta ótica, explicita Touraine (2010, p. 36) que:

\footnotetext{
A ideia de sujeito implica a ideia de direito, e a ideia de direitos implica a democracia, definida como o governo da lei a serviço dos direitos, que são afirmados e defendidos pelos atores e pelos movimentos sociais, que falam em nome do sujeito, isto é, em nome do direito dos indivíduos terem direitos. Estas três noções são inseparáveis, da mesma forma que a dominação, o lucro e a revolução formam um conjunto. Sempre concluímos que a democracia e a revolução são opostas. A democracia não existe a não ser quando os direitos dos indivíduos e dos atores sociais podem ser defendidos dentro de um quadro institucional, isto é, pela lei. Mas o ser de direito não é um produto da democracia; ele é sua condição.
} 
Encerrada a Década da Mulher, não se encerraram os esforços pela busca da equidade de gênero, para tanto, menciona-se a Conferência de População no Cairo, em 1994, e a Conferência da Mulher em Beijing, em 1995. Esses são os documentos internacionais sobre direitos humanos das mulheres no Sistema Global de Proteção aos Direitos Humanos, embora exista menção nos demais tratados sobre a necessidade de repudiar as diversas formas de discriminação baseadas no sexo.

Especificamente quanto à violência contra a mulher, no âmbito do sistema Interamericano de proteção aos Direitos Humanos, foi assinada a Convenção Interamericana para Prevenir, Punir e Erradicar a Violência contra a Mulher (conhecida como Convenção Belém do Pará), ratificada pelo Brasil em 1995 (GONÇALVES, 2011).

Em relação aos direitos sexuais e reprodutivos, foi somente em 1994, no relatório da Conferência Internacional sobre População e Desenvolvimento, que tais direitos foram reconhecidos como integrantes ao rol de direitos humanos (GONÇALVES, 2011):

Princípio 4 O progresso na igualdade e equidade dos sexos, a emancipação da
mulher, a eliminação de toda espécie de violência contra ela e a garantia de poder
ela própria controlar sua fecundidade são pedras fundamentais de programas
relacionados com população e desenvolvimento. Os direitos humanos da mulher e
da menina são parte inalienável, integral e indivisível dos direitos humanos
universais. A plena e igual participação da mulher na vida civil, cultural, econômica,
política e social, nos âmbitos nacional, regional e internacional, e a erradicação de
todas as formas de discriminação com base no sexo são objetivos prioritários da
comunidade internacional. (NAÇÕES UNIDAS, 1994)

Após, diversos documentos internacional endossaram a ideia de direitos humanos particularizados para as mulheres. Assim, verifica-se que a temática de direitos humanos das mulheres na esfera privada passou "paulatinamente da obscuridade ao reconhecimento formal em documentos internacionais" (GONÇALVES, 2011, p. 75).

Conforme Bordieu (2005) o papel de dominação simbólico na sociedade alicerçado na estruturação do espaço e na organização social, acabou por deixar a mulher invisível, restrita ao ambiente doméstico, sendo representada em público pelo chefe de família (o pai, irmão ou marido). Assim, embora tardiamente os direitos humanos particularizados às mulheres estão sendo reconhecidos, embora a garantia desses direitos necessite de maior atenção, especialmente aqueles sobre o próprio corpo, ligados a reprodução, sexualidade e violência. 


\section{CONCLUSÃO}

O presente trabalho teve como objetivo principal compreender a atuação do sistema internacional de proteção dos direitos humanos na garantia dos direitos de proteção particulares das mulheres. Através da conceituação do que são direitos humanos genericamente, pretendeu-se abordar mais especificamente os direitos humanos das mulheres. Nesse sentido, contata-se a inexistência de um conceito fechado sobre o que são tais direitos.

Ainda assim, é possível afirmar que direitos humanos são valores construídos e reconhecidos a partir do processo histórico por decisões de caráter político e de conveniência social. Portanto, se são reflexos de construções históricas, estes são impactados pelas mudanças sociais, o que implica no reconhecimento de direitos particularizados às mulheres. Pode-se afirmar, portanto que o conceito do que constituem direitos humanos seria diferente se as mulheres tivessem interagido ativamente durante o processo de construção social e política.

Temas como aborto, estupro, violência doméstica, assédio sexual e moral, mutilação genital, direitos reprodutivos, maternidade, dificuldade no controle de sua vida expressam a necessidade de direitos humanos particularizados às mulheres. Ou seja, mesmo que as mulheres possam ser vítimas de violações de direitos humanos que atingem os homens, elas experimentam ainda, pela sua capacidade biológica (especialmente reprodutiva) e pela construção social e cultural, formas distintas de violações aos direitos humanos.

Portanto, além de cultural a diferença sexual também é uma diferença política ligada a falta de liberdade e de direitos das mulheres e sua histórica sujeição ao masculino em faca da organização social e das hierarquias de poder. Portanto a desigualdade entre homens e mulheres surgiu da relação de poder entre os sexos e está alicerçado na intimidade humana, sendo propagada igualmente por ambos.

Dessa forma, destaca-se a contribuição do movimento feminista, que através da militância, bem como pela academia, permitiu uma discussão sobre os papéis femininos e masculinos na sociedade, especialmente após os anos 1960. Esse debate foi importante para a criação de iniciativas legislativas que visassem a defesa dos direitos das mulheres.

Nesse sentido, o reconhecimento internacional opera de maneira eficiente nessa proteção e garantia ao envolver fontes de pressão internacionais que são muitas vezes mais eficazes para alcançar o tão almejado reconhecimento interno por parte do Estado. Assim, estes direitos estão alicerçados na proteção da liberdade dos indivíduos, na igualdade e na 
necessária e equilibrada intervenção do Poder Público no ambiente doméstico, conceito que era inimaginável até pouco tempo.

\title{
THE IMPACT OF GENDER CONCEPTS FOR THE GUARANTEE OF HUMAN RIGHTS FOR THE PROTECTION OF WOMEN
}

\begin{abstract}
If the internationalization of human rights granted to every person is recent, the recognition of individualized rights to women is even more. This need for rights of its own is necessary for ensuring equality and protection of women, while human being is exposed to very specific aggressions such as domestic violence, rape, harassment in public places, difficulty of admission in the spaces of power, anyway. From this premise, we discuss in this article the Human Rights of women and the international legal system of protection. Thus, it is intended to answer the problem: How the gender issue can impact human rights and ensure the protection of women? Therefore, it is intended to understand the role of the international system of human rights protection in ensuring the particular protection of women's rights. Thereby, initially aimed to conceptualize what are human rights to, after, understand the contribution of gender plots for the human rights of women and its international recognition. The research technique used was the literature (articles and books) and documentary. In turn, the method used was the hypothetical-deductive, starting from the analysis of what are human rights generally to, after, seek more specific reference regarding the need for recognition of human rights particularized to women. It finds that, although the feminist movement that began in the 1960s have had their achievement, the protection and guarantee of these rights still need to be accomplished and discussed in order to avoid social regression.
\end{abstract}

Keywords: Human rights of women; feminine empowerment; equality; internationalization of human rights.

\section{Referências}

AQUINO, Quelen B.; PORTO, Rosane.T.C.. Cidadania, políticas públicas e transformações de gênero: a emancipação da mulher. In: CUSTÓDIO, A. V.; POFFO, G. D.; SOUZA, I. F.. (Org.). Direitos Fundamentais e Políticas Públicas. 1ªed.Balneário Camboriú: Avantis, 2013, v. 1, p. 405-416.

ARENDT, Hannah. As origens do totalitarismo. Rio de Janeiro: Paz e Terra, 1979.

ARENDT, Hannah. Sobre a revolução. São Paulo: Companhia das Letras, 2011.

BEAUVOIR, Simone de. O Segundo Sexo. Vol II. 2 ed. Rio de Janeiro: Nova Fronteira, 2009.

BOBBIO, Norberto. A era dos direitos. Rio de Janeiro: Campos, 1992. 
BOURDIEU, Pierre. A Dominação Masculina. 4º ed. Rio de Janeiro: Bertrand Brasil, 2005.

CORREIA, Theresa Rafael Couto. Corte Interamericana de Direitos Humanos:

Repercussão Jurídica das Opiniões Consultivas. Curitiba: Juruá, 2008.

DESOUZA, Eros;BALDWIN, John R. ;ROSA, Francisco Heitor da. A construção social dos papéis sexuais femininos. Psicologia: Reflexão e Crítica, Porto Alegre, v. 13, n. 3, p. 485496, 2000. Disponível em: <http://www.scielo.br/ pdf/ prc/ v13n3/ v13n3a16.pdf>. Acesso em: 05 Ago. 2015.

DUARTE, M. M. G. Tirania no próprio ninho: violência doméstica e direitos humanos da mulher: motivos da violência de gênero, deveres do estado e proposta para o enfrentamento efetivo. Santa Cruz do Sul: Essere nel Mondo, 2015. E-book.

FERNANDES, Pádua. Para que servem os direitos humanos? Coimbra: Olhar-te, 2009.

FERNÁNDEZ-LARGO, Antonio Osuna. Pilares para a fundamentação dos Direitos Humanos. Santa Cruz do Sul: Edunisc. 2006.

GONÇALVES, Tamara Amoroso. Direitos humanos das mulheres e a Comissão

Interamericana de Direitos Humanos: uma análise de casos admitidos entre 1970 e 2008. Dissertação (Mestrado) - Programa de Pós Graduação em Direitos Humanos da Faculdade de Direito, Universidade de São Paulo. Orientadora: Prof ${ }^{a}$. Dr ${ }^{a}$ Eva Alterman Blay. São Paulo, 2011. Disponível em: <http://www.teses.usp.br/teses/disponiveis/2/2140/tde-31052012162759/pt-br.php>. Acesso em: 10 jun. 2016.

GORCZEVSKI, Clovis. Direitos humanos, educação e cidadania: conhecer, educar, praticar. Santa Cruz do Sul: Edunisc, 2009

HERKENHOFF, João Batista. Gênese dos direitos humanos. São Paulo: Acadêmica, 1994.

JULIOS-CAMPUZANO, Alfonso de. Os Desafios da Globalização: Modernidade, Cidadania e Direito Humanos. Tradução de Clovis Gorczevski. Santa Cruz do Sul: EDUNISC, 2008.

NAÇÕES UNIDAS. Relatório da Conferência Internacional sobre População e

Desenvolvimento. Cairo, 1994. Disponível em: <http://www.unfpa.org.br/Arquivos/relatoriocairo.pdf>. Acesso em: 10 jun. 2016.

ORGANIZAÇÃO DAS NAÇÕES UNIDAS (ONU). Declaração universal dos direitos humanos. Assembleia Geral da ONU, 1948. Disponível em: <http://www.dudh.org.br /wpcontent/uploads/2014/12/dudh.pdf.>. Acesso em: 5 abr. 2016.

PATEMAN, Carole. O Contrato Sexual. Tradução de Marta Avancini. Rio de Janeiro: Paz e Terra, 1993.

PENIDO, Laís de Oliveira. Legislação, equidade de gênero e cultura patriarcal brasileira: uma relação difícil. In: PENIDO, Laís de Oliveira (Coord.). A igualdade de gêneros nas relações de trabalho. Brasília: Escola Superior do Ministério Público da União, 2006, p. 270280. 
PIOVESAN, Flávia. Direitos humanos das mulheres no Brasil: desafios e perspectivas. In: PENIDO, Laís de Oliveira (Coord.). In: PENIDO, Laís de Oliveira (Coord.). Brasília: Escola Superior do Ministério Público da União, 2006, Brasília: Escola Superior do Ministério Público da União, 2006, p. 205-212.

PIOVESAN, Flávia. Direitos humanos e justiça internacional: um estudo comparativo dos sistemas regionais europeu, interamericano e africano. 5. Ed. São Paulo: Saraiva, 2014.

SCHWINN, Simone. Proteção internacional dos direitos humanos: um breve estudo comparativo entre o sistema global e o americano. In.: Gorczevski, Clóvis (org.). Direitos humanos e participação política. Porto Alegre: Imprensa livre, 2011.

THERBORN, Göran. Sexo e poder: a família no mundo 1900-2000. Tradução de Elisabete Dória Bilac. São Paulo: Contexto, 2006.

TOURAINE, Alain. O mundo das mulheres. Petrópolis: Vozes, 2007.

TRINDADE, Antônio Augusto Cançado. A humanização do direito internacional. Belo Horizonte: Del Rey, 2006.

\section{Sobre as autoras:}

Analice Schaefer de Moura é Mestranda em Direito pelo Programa de Pós Graduação em Direito da Universidade de Santa Cruz do Sul - Conceito Capes 5, com Taxa PROSUP/CAPES. Linha de pesquisa: Políticas Públicas de Inclusão Social. Integrante do Grupo de Pesquisa "Direito, Cidadania e Políticas Públicas", vinculado ao PPGD - UNISC. Graduada pela mesma Universidade. Advogada OAB/RS 103034. E-mail: analice_sm@hotmail.com

Letícia Thomasi Jahnke é Doutoranda em Direito na Universidade de Santa Cruz do Sul, na linha de pesquisa Diversidade e Políticas Públicas, orientanda da Prof. Dra. Marli Marlene Moraes da Costa. Mestre em Direito da Universidade Regional Integrada do Alto Uruguai e das Missões - Campus Santo Ângelo, na linha de pesquisa de Direitos Especiais, com bolsa institucional. Especialista em Direito Processual Civil: Visão Atual, Novas Perspectivas, pela Universidade Luterana do Brasil - ULBRA (2012). Especialista em Direito Civil com Ênfase em Família, Sucessões e Mediação, pela Universidade Luterana do Brasil - ULBRA (2012). Graduada em Direito pela Universidade Luterana do Brasil (2010). Atuante em projetos de pesquisa. Líder do Grupo de Pesquisa Políticas Públicas e Direitos Especiais (ULBRA), registrado pelo CNPq. Coordenadora do Programa Institucional Continuado de Formação Humana - PFH da Universidade Luterana do Brasil - Campus Santa Maria. Coordenadora do Programa de Pós-Graduação Especialização em Direito Médico e da Saúde. Integrante do projeto de pesquisa "Gestão sistêmica e sustentável do meio ambiente urbano santamariense", financiado pela ULBRA. Professora Adjunta do Curso de Direito na Universidade Luterana do Brasil - Campus Santa Maria. Professora Substituta do Departamento de Direito da Universidade Federal de Santa Maria - UFSM (2015). Possui trabalhos apresentados e publicados em eventos nacionais e internacionais, bem como possui organização de livros e capítulos de livros publicados. E-mail: leticia.thomasi@ hotmail.com 